\title{
Expression and survival significance of B-cell-specific Moloney murine leukemia virus integration site 1 and matrix metalloproteinase-9 in non-small-cell lung cancer
}

\author{
MINGKUI MU, YANG SONG and BIN ZHANG \\ Institute of Hard Tissue Development and Regeneration, The Second Affiliated Hospital of Harbin Medical University, \\ Harbin, Heilongjiang 150086, P.R. China
}

Received May 30, 2014; Accepted August 5, 2016

DOI: $10.3892 / 01.2016 .5209$

\begin{abstract}
One of the main challenges in lung cancer research is identifying patients at high risk of progression and metastasis following surgical resection. In the present study, the prognostic significance of B-cell-specific Moloney murine leukemia virus integration site 1 (BMI1) and matrix metalloproteinase-9 (MMP9) in non-small-cell lung cancer (NSCLC) was evaluated. BMI1 and MMP9 expression in tumors from 132 surgical NSCLC patients [squamous cell carcinoma (SCC), n=79; and adenocarcinoma (AD), $n=53$ ] was evaluated by immunohistochemistry. The clinical significance was determined using multivariate Cox regression analysis, Kaplan-Meier curves and the log-rank test. High BMI1 expression was more frequent in SCC compared with that in $\mathrm{AD}(\mathrm{P}=0.015)$. Comparisons between the expression of BMI1 and that of other known biological markers revealed that the expression of BMI1 was correlated with that of MMP9 $\left(\chi^{2}=4.241, \mathrm{P}=0.039\right)$ in SCC. Although an association was not identified between high BMI1 expression and overall survival (OS) in NSCLC or AD, high BMI1 expression was an unfavorable predictor of survival in SCC according to the survival curves $(\mathrm{P}=0.038)$. In addition, combined high BMI1 and MMP9 expression levels were significantly correlated with SCC nodal/distant metastasis $\left(\chi^{2}=6.392, \mathrm{P}=0.014\right)$. Multivariate Cox proportional model analysis demonstrated that this combined marker was an independent prognostic indicator of $\mathrm{OS}$ in SCC $(\mathrm{P}=0.025$; hazard ratio $=12.963$; 95\% confidence interval: $1.142-7.637)$. Therefore, this study demonstrated that combined BMI1 and MMP9 expression may be used as a marker for the progression and metastasis of
\end{abstract}

Correspondence to: Dr Bin Zhang, Institute of Hard Tissue Development and Regeneration, The Second Affiliated Hospital of Harbin Medical University, 150 Baojian Road, Harbin, Heilongjiang 150086, P.R. China

E-mail: xy8990102@163.com

Key words: squamous cell carcinoma, immunohistochemistry, B-cell-specific Moloney murine leukemia virus integration site 1, matrix metalloproteinase-9, overall survival
SCC. These results may aid in the elucidation of the potential mechanism underlying the involvement of BMI1 and MMP9 in tissue-specific SCC progression.

\section{Introduction}

Lung cancer is the leading cause of cancer-related mortality worldwide, with $\sim 1.4$ million deaths recorded annually (1). Approximately $80 \%$ of all lung cancers are classified as non-small-cell lung cancer (NSCLC), which may be divided phenotypically into two principal subtypes, namely squamous cell carcinoma (SCC) and adenocarcinoma (AD). SCC and AD are often treated similarly; however, they differ not only pathologically, but also in terms of gene expression levels, clinical manifestation and response to targeted therapeutic agents (2-4). Early detection is key to prolonging patient survival; thus, it is crucial to identify molecular markers that predict prognosis and design novel treatment strategies for SCC and AD (5).

The B-cell-specific Moloney murine leukemia virus integration site 1 (BMI1) gene, a member of the polycomb-group $(\mathrm{PcG})$ proteins, was first isolated as an oncogene that acts synergistically with c-Myc in the oncogenesis of murine lymphomas (6,7). BMI1 functions as a transcriptional repressor of BMI1 and c-Myc target genes via an epigenetic mechanism (8). In addition, deregulation of BMI1 gene expression leads to cell proliferation and tumor progression $(8,9)$. Aberrant BMI1 expression has been associated with a number of solid and hematological malignancies (10-18), including NSCLC (19-28). Although the clinicopathological and prognostic significance of high BMI1 expression in NSCLC has been investigated, the results have been inconsistent. For example, certain studies suggested that BMI1 overexpression is associated with poor prognosis in SCC (26); however, Vrzalikova et al (22) found no correlation between BMI1 expression and overall survival (OS) in their cohort, which had a preponderance of SCCs.

Matrix metalloproteinase-9 (MMP9), a member of the MMP class of gelatinases, plays a major role in the invasiveness and metastasis of NSCLC, mainly through specific induction by vascular endothelial growth factor receptor-1 (VEGFR-1) $(29,30)$. Jiang et al (31) reported that BMI1 activated nuclear factor- $\kappa \mathrm{B}$ $(\mathrm{NF}-\kappa \mathrm{B})$ and subsequently upregulated MMP9 expression, leading to increased migration and invasion of glioma cells; 
Li et al (32) demonstrated that BMI1 contributed to the invasion and metastasis of hepatocellular carcinoma by increasing MMP9 and VEGF expression via the phosphoinositide-3-kinase/protein kinase B (PI3K/Akt) pathway. However, the number of studies on the interaction between BMI1 and MMP9 in NSCLC progression and metastasis is limited.

In this study, a survival analysis of BMI1, MMP9 and their combined expression as a marker in lung SCC and AD samples was performed. The aim was to determine whether the combined high BMI1 and MMP9 expression levels predict poor survival in SCC. These results may help elucidate the mechanism underlying tumor progression and metastasis in patients with NSCLC and ultimately identify novel diagnostic and/or prognostic markers.

\section{Patients and methods}

Patients and histopathology. The study samples consisted of paraffin-embedded lung tissue samples from 135 patients diagnosed with NSCLC who had undergone surgery between January, 2008 and January, 2009 at the Second Affiliated Hospital of Harbin Medical University (Harbin, China). According to the World Health Organization guidelines (33), the cases were classified as SCC or AD. In total, 132 cases were analyzed $(A D, n=79$; and $S C C, n=53)$. Of the 132 cases, 10 were well-differentiated, 57 were moderately and 65 were poorly differentiated. The pathological tumor stage distribution was I-IV according to the American Joint Committee on Cancer (34). All the patients were followed up until October, 2013 or until death. The median follow-up duration for survivors was 43.15 months (range, 1.30-62.40 months). The patient population comprised 89 men and 43 women (male:female ratio, 2.07:1) and the median age was 61 years (range, 34-80 years). All the cases representing a spectrum of NSCLC were retrieved from the records of the Second Affiliated Hospital of Harbin Medical University. The Ethics Committee of the hospital granted permission for the study.

Immunohistochemical (IHC) evaluation. The expression of BMI1 and MMP9 in the 132 patients with NSCLC was investigated. Paraffin-embedded sections were processed as previously described $(25,27)$. Briefly, the sections were deparaffinized in xylene and rehydrated in a graded series of ethanol. The sections were subsequently submerged in ethylene diamine tetraacetic acid ( $\mathrm{pH} 8.0)$ and autoclaved at $121^{\circ} \mathrm{C}$ for $5 \mathrm{~min}$ to retrieve antigenicity. Endogenous peroxidase was quenched with $3 \% \mathrm{H}_{2} \mathrm{O}_{2}$ for $15 \mathrm{~min}$. Following washing with PBS, the sections were incubated with anti-BMI1 (dilution, 1:80; LS-C98480; LifeSpan Biosciences, Seattle, WA, USA) and anti-MMP9 (dilution, 1:800; ab38898; Abcam, MA, USA) antibodies overnight at $4^{\circ} \mathrm{C}$. The sections were incubated with peroxidase-conjugated streptavidin for $30 \mathrm{~min}$ and the reaction products were visualized with the chromogen diaminobenzidine and counterstained with commercial hematoxylin. The percentage of positive cells was determined by counting 500 cells in five random fields per section. Nuclear and cytoplasmic immunostaining was evaluated using semi-quantitative assessment, in which the percentage of positive cells was calculated (25). The percentage of positive cells was determined by counting 500 cells in five random areas per section. IHC staining of the cells was scored according to the following criteria: -, no staining; +, 1-10\%; ++, 10-50\%; ,$+++ 50-75 \%$; and,$++++ 75-100 \%$ cells stained. The IHC scores for BMI1 and MMP9 expression were classified as low $(-$ and +$)$ and high $(++,+++$ and ++++$)$.

Statistical analysis. The association between factors was evaluated using Pearson's $\chi^{2}$ test. Cumulative OS curves were plotted using the Kaplan-Meier method and log-rank statistics were used to determine differences between groups. Covariates that remained significant through the univariate analysis were selected for the multivariate analysis. Cox regression was used for the multivariate analysis, with a backward stepwise elimination model. $\mathrm{P}<0.05$ was considered to indicate statistical significance. Two-sided tests were used throughout. Statistical calculations were performed using SPSS 19.0 software (IBM SPSS, Armonk, NY, USA).

\section{Results}

BMII is overexpressed in NSCLC tissues. On IHC analysis, the majority of cells in NSCLC tissues, including SCC and AD cells, were strongly stained, indicating high expression of BMI1. BMI1 was highly expressed in 95/132 NSCLC cases $(72.0 \%)$ and 63/79 SCC cases (79.7\%) (Fig. 1). The expression of BMI1 in SCC was higher compared with that in AD (79.7 vs. $60.4 \%$, respectively; $\mathrm{P}=0.015)$. BMI1 was highly expressed in $32 / 53$ (60.4\%) AD cases. Similar to BMI1, MMP9 expression was detected in NSCLC tissues and its expression level was higher in SCC compared with that in $\mathrm{AD}(\mathrm{P}=0.012$, Fig. 1).

Correlations of BMII, MMP9 and combined marker expression with variables in NSCLC samples. BMI1 expression was compared with known clinicopathological factors and biological markers in the NSCLC samples. There was a positive correlation between the expression of BMI1 and that of MMP9 in the SCC samples $\left(\chi^{2}=4.241, \mathrm{P}=0.039\right.$; Table I). Combined marker expression in the SCC samples was found to be significantly correlated with metastasis $\left(\chi^{2}=6.392, \mathrm{P}=0.014\right.$; Table II), but not with other clinical parameters in all lung cancer or AD cases.

BMI1 protein expression predicts OS in NSCLC. To determine whether BMI1 expression was an independent prognostic factor for OS in NSCLC, multivariate Cox regression analyses were performed. Among the immunological variables analyzed in this study, BMI1 expression was not associated with clinical outcome in the entire cohort. When analysis was stratified according to the major histological subtypes, the results suggested that BMI1 expression was an unfavorable prognostic factor in SCC $(\mathrm{P}=0.038$; hazard ratio $=2.861$; 95\% confidence interval: 1.013-8.083; Table III and Fig. 2A). In $\mathrm{AD}, \mathrm{BMI} 1$ tended to be a negative prognostic factor for long-term survival, although the difference was not statistically significant $(\mathrm{P}=0.203$; hazard ratio $=1.633 ; 95 \%$ confidence interval: 0.762-3.501; Fig. 2B).

BMI1 and MMP9 protein expression predicts $O S$ in SCC. Although MMP9 protein levels did not predict OS in NSCLC or its histological subtypes, the combination of high and low protein expression of BMI1 and MMP9 identified four 
Table I. Correlation between BMI1 and MMP9 protein expression in squamous cell carcinoma.

\begin{tabular}{|c|c|c|c|c|c|}
\hline \multirow{2}{*}{$\begin{array}{l}\text { BMI1 } \\
\text { expression, } \\
\mathrm{n}(\%)\end{array}$} & \multicolumn{3}{|c|}{ MMP9 expression, n (\%) } & \multirow[b]{2}{*}{$\chi^{2}$} & \multirow[b]{2}{*}{ P-value } \\
\hline & High & Low & Total & & \\
\hline High & $48(60.8)$ & $15(19.0)$ & $63(79.8)$ & 4.241 & $0.039^{\mathrm{a}}$ \\
\hline Low & $8(10.1)$ & $8(10.1)$ & $16(20.2)$ & & \\
\hline Total & $56(70.9)$ & $23(29.1)$ & 79 (100) & & \\
\hline
\end{tabular}

${ }^{a} \mathrm{P}<0.05$ was considered to indicate statistically significant differences. High expression, immunohistochemical (IHC) scores ++, +++ and ++++; low expression, IHC scores - and +. BMI1, B-cell-specific Moloney murine leukemia virus integration site 1; MMP9, matrix metalloproteinase-9.

\section{BMI1}
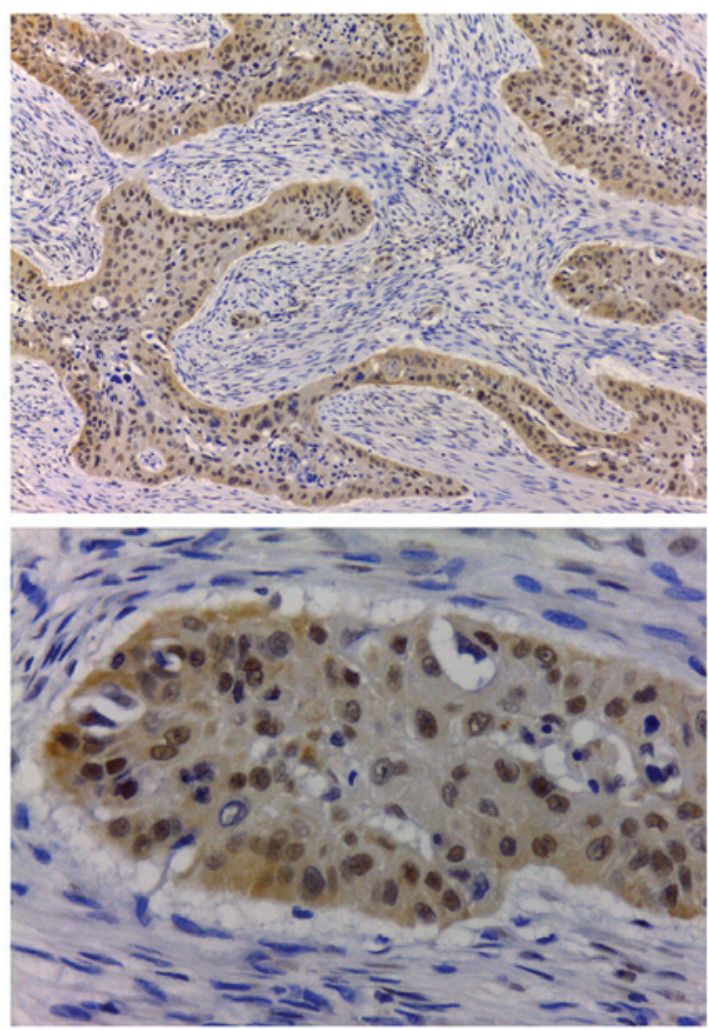

MMP9
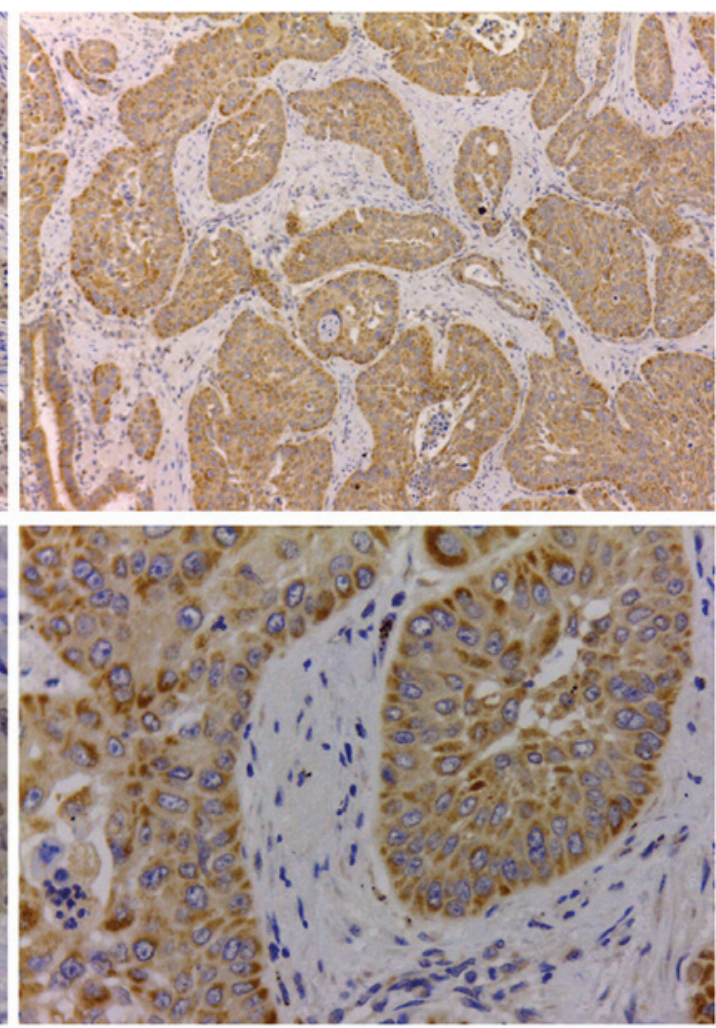

Figure 1. Representative immunohistochemical staining for BMI1 and MMP9 in an adenocarcinoma case. The sections were stained with BMI1- or MMP9-specific antibodies and counterstained with hematoxylin (upper panels: magnification, x100; lower panels: magnification, x400). BMI1, B-cell-specific Moloney murine leukemia virus integration site 1; MMP9, matrix metalloproteinase-9.

subgroups with distinct outcomes in SCC (Fig. 2C). The combination of high expression of BMI1 and MMP9 (Cluster B) was associated with shorter OS compared with low BMI1 and high MMP9 expression (Cluster A: High BMI1/low MMP9; low BMI1/high MMP9; and low BMI1/low MMP9). However, BMI1, MMP9 and combined marker expression were not significant prognostic factors in AD (Fig. 2D-F).

\section{Discussion}

Similar to other cancer types, lung cancer development is the result of a stepwise progression of malignant transformation of the normal respiratory epithelium (35). The classification of lung cancer by Noguchi (35) identifies atypical adenomatous hyperplasia and cancer in situ as preinvasive neoplastic lung lesions that serve as precursors of invasive lung cancer through a progressive transformation into two types, characterized by survival outcome (35). Well-designed molecular biology investigations may be used for tumor classification, response prediction, assigning prognosis or even as therapeutic targets (36). SCC and AD share a range of similarities, but there are also differences $(2,4,17)$. Therefore, identification of the roles of molecular markers in differential prediction of outcome is important in SCC and AD.

The BMI1 gene, which encodes a PcG protein, was first isolated as an oncogene that acts synergistically with c-Myc 


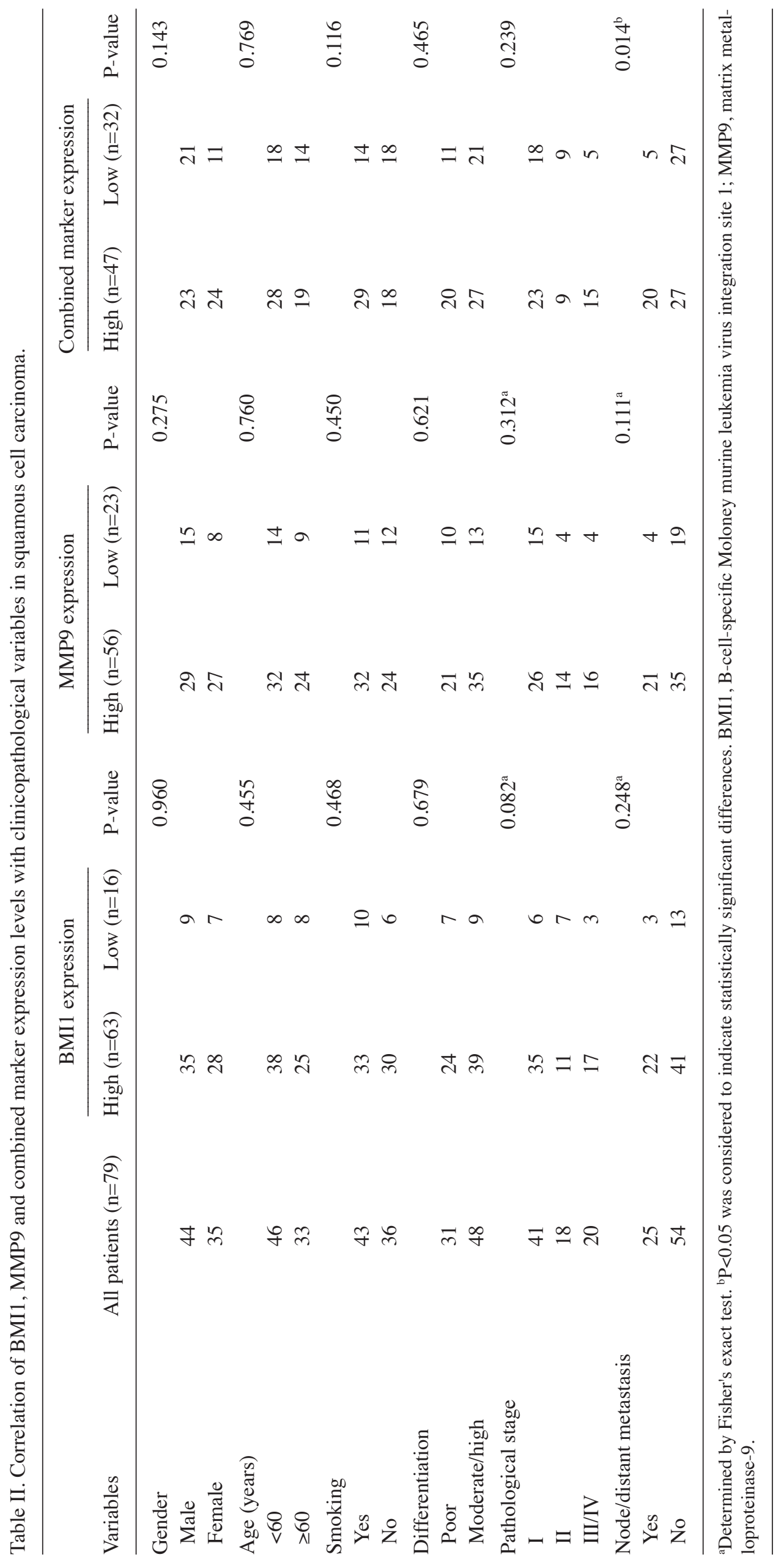


Table III. Univariate and multivariate analyses of overall survival for 79 patients with squamous cell lung carcinoma.

\begin{tabular}{|c|c|c|c|c|}
\hline \multirow[b]{2}{*}{ Variables } & \multicolumn{2}{|c|}{ Univariate analysis } & \multicolumn{2}{|c|}{ Multivariate analysis } \\
\hline & HR $(95 \% \mathrm{CI})$ & P-value & HR $(95 \% \mathrm{CI})$ & P-value \\
\hline Age ( $\geq 60$ vs. $<60$ years $)$ & $1.082(0.992-1.179)$ & 0.070 & & \\
\hline Gender (male vs. female) & $0.453(0.134-1.414)$ & 0.166 & & \\
\hline Smoking status (yes vs. no) & $1.260(0.284-5.595)$ & 0.180 & & \\
\hline Differentiation (poor vs. moderate/high) & $0.233(0.675-1.287)$ & 0.233 & & \\
\hline Pathological stages (III/IV vs. II vs. I) & $1.657(0.889-3.089)$ & 0.112 & & \\
\hline Node/distant metastasis (yes vs. no) & $2.551(1.352-4.814)$ & $0.004^{\mathrm{a}}$ & $17.163(1.621-5.816)$ & $0.001^{\mathrm{a}}$ \\
\hline BMI1 (positive vs. negative) & $2.861(1.013-8.083)$ & $0.038^{\mathrm{a}}$ & & \\
\hline MMP9 (positive vs. negative) & $2.157(0.092-4.888)$ & 0.066 & & \\
\hline Combined markers (cluster B vs. cluster A) & $3.085(1.466-6.491)$ & $0.002^{\mathrm{a}}$ & $2.963(1.142-7.637)$ & $0.025^{\mathrm{a}}$ \\
\hline
\end{tabular}

${ }^{\mathrm{a}} \mathrm{P}<0.05$ was considered statistically significant. HR, hazards ratio; $\mathrm{CI}$, confidence interval.

Table IV. Summary of recently published studies on the correlation between BMI1 expression and clinicopathological factors or OS .

\begin{tabular}{|c|c|c|c|c|c|}
\hline \multirow[b]{2}{*}{ Study (Refs.) } & \multirow[b]{2}{*}{ Year } & \multirow[b]{2}{*}{ Cases (n) } & \multirow[b]{2}{*}{ Histology } & \multicolumn{2}{|l|}{ Correlation } \\
\hline & & & & Clinicopathological factors & OS \\
\hline Zhang et al (28) & 2014 & 178 & $\mathrm{AD}$ & pStage & Yes \\
\hline Hu et al (25) & 2012 & 114 & NSCLC & $\begin{array}{l}\text { Tumor size, differentiation, } \\
\text { pT classification, } \\
\text { pN classification, pStage }\end{array}$ & Yes \\
\hline Huang et al (26) & 2012 & 56 & SCC & $\begin{array}{l}\text { Tumor size, } \\
\text { lymph node metastasis, } \\
\text { distant metastasis }\end{array}$ & No analysis \\
\hline Zhang et al (23) & 2010 & 134 & $\mathrm{AD}$ & pStage & Yes \\
\hline Vrzalikova et al (22) & 2008 & 179 & NSCLC & pStage & No \\
\hline Vonlanthen et al (19) & 2001 & 48 & NSCLC & No & No \\
\hline
\end{tabular}

pStage, pathological stage; BMI1, B-cell-specific Moloney murine leukemia virus integration site 1; OS, overall survival; AD, adenocarcinoma; NSCLC, non-small-cell lung cancer; SCC, squamous cell carcinoma.

in the oncogenesis of murine lymphomas $(4,6)$. BMI1 functions as a transcriptional repressor of their target genes via an epigenetic mechanism (2). A number of studies have reported that BMI1 is upregulated in a variety of human malignancies, including lung (19), breast (11), gastric (13), hepatocellular (12) and esophageal (17) cancer, non-Hodgkin lymphoma (10) and cervical (15) cancer, suggesting that BMI1 is a potential oncogene. As a member of the PcG family, BMI1 plays a suppressive role, targeting cyclin-dependent kinase inhibitor $2 \mathrm{~A}$ $\left(\mathrm{p} 16^{\mathrm{INK} 4 \mathrm{~A}}\right)$ and cyclin-dependent kinase 2 -associated protein 2 $\left(\mathrm{p} 14^{\mathrm{ARF}}\right)(21,37,38)$, and promotes cell proliferation by suppressing the p16/retinoblastoma and/or p14 ${ }^{\mathrm{ARF}} /$ mouse double minute 2/p53 pathways $(39,40)$. Furthermore, it has been reported that BMI1 may downregulate transcription of the tumor suppressor phosphatase and tensin homolog deleted on chromosome 10 (PTEN) via direct association with the PTEN gene locus (32). BMI1 upregulation also induces epithelial-to-mesenchymal transition and promotes human SCC occurrence, aggressiveness, invasion and metastasis by downregulating E-cadherin and upregulating vimentin expression (26).

In this study, the expression of BMI1 in NSCLC samples was investigated. BMI1 was found to be significantly overexpressed in SCC compared with AD tissues. However, the present findings are contradictory to those of previous studies $(22,25)$, which stated that BMI1 expression is not correlated with pathological type. Vrzalikova et al (22) reported a trend for higher BMI1 expression in SCC compared with AD, although the difference was not statistically significant. The discrepancies across studies may be due to the different immunohistochemistry protocols used, including antibody dilution, development time and positivity criteria applied, particularly the score used to discriminate positivity.

The present study demonstrated that high expression of BMI1 is associated with shorter OS and indicates that BMI1 expression confers an aggressive phenotype to human SCC. Current opinions on the significance of BMI1 expression in lung cancer 

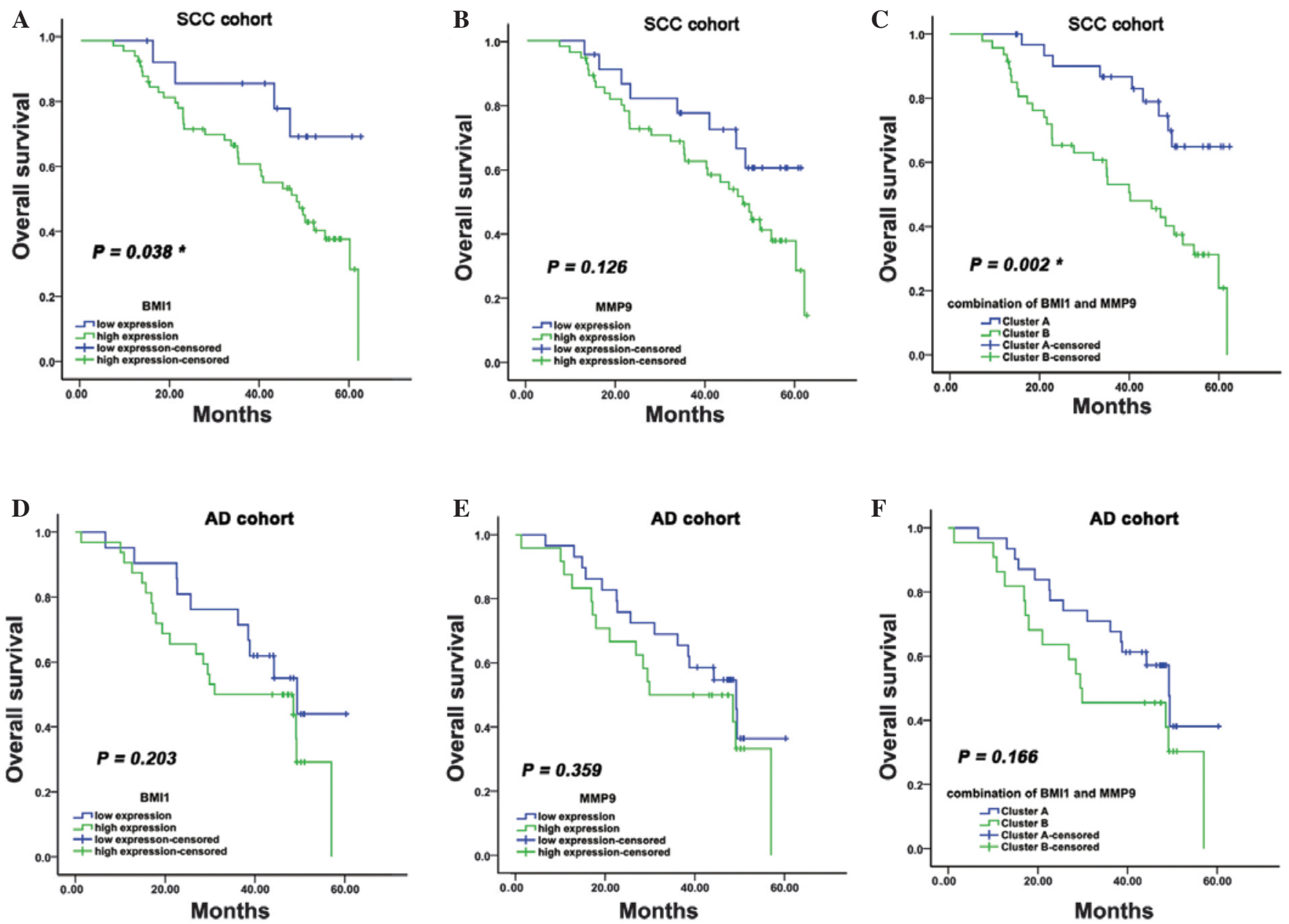

Figure 2. OS curves according to the level of BMI1, MMP9 and combined marker expression. (A and B) OS curves of 79 patients with SCC assessed by Kaplan-Meier analysis according to BMI1 and MMP9 expression. High BMI1 expression was significantly associated with shorter OS. (C) OS curves in SCC cases. OS for Cluster A (high BMI1/low MMP9, low BMI1/high MMP9 and lowBMI1/lowMMP9) was significantly shorter compared with that of Cluster B (high BMI1/high MMP9). (D and E) OS curves of 53 patients with AD assessed by Kaplan-Meier analysis according to BMI1 and MMP9 expression (F) OS curves in AD cases according to the combined marker expression as described in (C). ${ }^{*} \mathrm{P}<0.05$ was considered statistically significant. BMI1, B-cell-specific Moloney murine leukemia virus integration site 1; MMP9, matrix metalloproteinase-9; SCC, squamous cell carcinoma; AD, adenocarcinoma.

are diverse, and the effect of BMI1 expression on prognosis in patients with lung cancer remains controversial (Table IV). The present findings are similar to those of Huang et al (26), who reported that BMI1 induced epithelial-to-mesenchymal transition and enhanced lung SCC cell migration and invasiveness; however, they did not perform a correlation analysis between BMI1 and OS in their cohort of 56 SCC cases, but rather between BMI1 and nodal/distant metastasis. Notably, their cohort comprised a preponderance of cases with nodal/distant metastasis. The differences in patient clinicopathological factors between studies may explain this discrepancy.

Furthermore, the present study demonstrated that BMI1 expression is associated with MMP9 expression $(\mathrm{P}=0.039)$. Of note, the combination of high BMI1 and high MMP9 protein levels was found to be significantly correlated with nodal/distant metastasis and predicted poor OS in SCC $(\mathrm{P}=0.002)$. In human tumors, MMPs play a critical role in tissue remodeling during development in pathological processes, including inflammation, tissue repair, tumor invasion and metastasis $(41,42)$. MMP expression has been reported to be low in the majority of benign lesions and is significantly increased in the majority of malignancies $(43,44)$. Among MMPs, MMP9 is of particular interest, as it is considered to be a tumor angiogenic factor that acts through VEGF (45). In NSCLC, MMP9 promotes the invasion of tumor cells in vitro and significantly promotes lung metastasis, mainly through specific induction of VEGFR-1 $(29,30)$. Jiang et al (31) reported that BMI1 activates NF- $\mathrm{kB}$ and subsequently upregulates MMP9 expression, leading to increased migration and invasion of glioma cells. In hepatocellular carcinoma, Li et al (32) reported that BMI1 overexpression contributed to invasion and metastasis by increasing MMP9 expression via the PTEN/PI3K/Akt pathway. However, the BMI1-MMP9 interaction in NSCLC invasion and metastasis is poorly understood. The present results indicate that the combination of high BMI1 and high MMP9 expression, rather than high BMI1 expression alone, is an independent prognostic indicator of OS in SCC. We hypothesize that there is a BMI1-MMP9 signaling pathway in SCC and that its activity promotes SCC progression and metastasis, although current models do not fully explain the complex interactions between BMI1 and MMP9.

In conclusion, BMI1 is upregulated in lung SCC tissues compared with AD tissues, and BMI1 expression is associated with adverse prognosis of SCC. BMI1 expression is associated 
with that of MMP9, and the combination of high BMI1 and high MMP9 protein levels are significantly correlated with nodal/distant metastasis. Additionally, the combined marker expression is an independent prognostic indicator of OS in SCC. The potential mechanism underlying the involvement of BMI1 and MMP9 in tissue-specific SCC progression requires further elucidation by future studies.

\section{Acknowledgements}

The authors would like to thank Professor Liu and Ms. Li for their assistance with collecting patient information.

\section{References}

1. Siegel R, Naishadham D and Jemal A: Cancer statistics, 2012. CA Cancer J Clin 62: 10-29, 2012.

2. Sy SM, Wong N, Lee TW, et al: Distinct patterns of genetic alterations in adenocarcinoma and squamous cell carcinoma of the lung. Eur J Cancer 40: 1082-1094, 2004.

3. Arriagada R, Bergman B, Dunant A, Le Chevalier T, Pignon JP and Vansteenkiste J; International Adjuvant Lung Cancer Trial Collaborative Group: Cisplatin-based adjuvant chemotherapy in patients with completely resected non-small-cell lung cancer. N Engl J Med 350: 351-360, 2004.

4. Bruno A, Focaccetti C, Pagani A, et al: The proangiogenic phenotype of natural killer cells in patients with non-small cell lung cancer. Neoplasia 15: 133-142, 2013.

5. Scott WJ, Howington J, Feigenberg S, Movsas B and Pisters K: Treatment of non-small cell lung cancer stage I and stage II: ACCP evidence-based clinical practice guidelines (2nd edition) Chest 132 Suppl 3: 234-242, 2007.

6. Haupt Y, Alexander WS, Barri G, Klinken SP and Adams JM: Novel zinc finger gene implicated as myc collaborator by retrovirally accelerated lymphomagenesis in $\mathrm{E}$ mu-myc transgenic mice. Cell 65: 753-763, 1991.

7. van Lohuizen M, Verbeek S, Scheijen B, Wientjens E, van der Gulden $\mathrm{H}$ and Berns A: Identification of cooperating oncogenes in E mu-myc transgenic mice by provirus tagging. Cell 65: 737-752, 1991.

8. van der Lugt NM, Domen J, Linders K, et al: Posterior transformation, neurological abnormalities and severe hematopoietic defects in mice with a targeted deletion of the bmi-1 proto-oncogene. Genes Dev 8: 757-769, 1994.

9. Satijn DP and Otte AP: RING1 interacts with multiple polycomb-group proteins and displays tumorigenic activity. Mol Cell Biol 19: 57-68, 1999.

10. van Kemenade FJ, Raaphorst FM, Blokzijl T, et al: Coexpression of BMI-1 and EZH2 polycomb-group proteins is associated with cycling cells and degree of malignancy in B-cell non-Hodgkin lymphoma. Blood 97: 3896-3901, 2001.

11. Kim JH, Yoon SY, Jeong SH, et al: Overexpression of Bmi-1 oncoprotein correlates with axillary lymph node metastases in invasive ductal breast cancer. Breast 13: 383-388, 2004.

12. Yonemitsu Y, Imazeki F, Chiba T, et al: Distinct expression of polycomb group proteins EZH2 and BMI1 in hepatocellular carcinoma. Hum Pathol 40: 1304-1311, 2009.

13. Li W, Li Y, Tan Y, Ma K and Cui J: Bmi-1 is critical for the proliferation and invasiveness of gastric carcinoma cells. J Gastroenterol Hepatol 25: 568-575, 2010.

14. Li DW, Tang HM, Fan JW, et al: Expression level of Bmi-1 oncoprotein is associated with progression and prognosis in colon cancer. J Cancer Res Clin Oncol 136: 997-1006, 2010.

15. Chen H, Zhou L, Wan G, Dou T and Tian J: BMI1 promotes the progression of laryngeal squamous cell carcinoma. Oral Oncol 47: 472-481, 2011.

16. Tong YQ, Liu B, Zheng HY, et al: BMI-1 autoantibody as a new potential biomarker for cervical carcinoma. PLoS One 6: e27804, 2011.

17. Choy B, Bandla S, Xia Y, et al: Clinicopathologic characteristics of high expression of Bmi-1 in esophageal adenocarcinoma and squamous cell carcinoma. BMC Gastroenterol 12: 146, 2012.

18. Xin T, Zhang FB, Sui GJ and Jin XM: Bmi-1 siRNA inhibited ovarian cancer cell line growth and decreased telomerase activity. Br J Biomed Sci 69: 62-66, 2012.
19. Vonlanthen S, Heighway J, Altermatt HJ, et al: The bmi-1 oncoprotein is differentially expressed in non-small cell lung cancer and correlates with INK4A-ARF locus expression. Br J Cancer 84: 1372-1376, 2001.

20. Breuer RH, Snijders PJ, Smit EF, et al: Increased expression of the EZH2 polycomb group gene in BMI-1-positive neoplastic cells during bronchial carcinogenesis. Neoplasia 6: 736-743, 2004.

21. Breuer RH, Snijders PJ, Sutedja GT, et al: Expression of the p16 (INK4a) gene product, methylation of the p16 (INK4a) promoter region and expression of the polycomb-group gene BMI-1 in squamous cell lung carcinoma and premalignant endobronchial lesions. Lung Cancer 48: 299-306, 2005.

22. Vrzalikova K, Skarda J, Ehrmann J, et al: Prognostic value of Bmi-1 oncoprotein expression in NSCLC patients: a tissue microarray study. J Cancer Res Clin Oncol 134: 1037-1042, 2008.

23. Zhang XY, Dong QG, Huang JS, et al: The expression of stem cell-related indicators as a prognostic factor in human lung adenocarcinoma. J Surg Oncol 102: 856-862, 2010.

24. Lee MO, Lee HJ, Kim MA, et al: p16Ink4a suppression of lung adenocarcinoma by Bmi-1 in the presence of p38 activation. J Thorac Oncol 6: 423-431, 2011.

25. Hu J, Liu YL, Piao SL, Yang DD, Yang YM and Cai L: Expression patterns of USP22 and potential targets BMI-1, PTEN, p-AKT in non-small-cell lung cancer. Lung Cancer 77: 593-599, 2012.

26. Huang J, Qiu Y, Chen G, Huang L and He J: The relationship between Bmi-1 and the epithelial-mesenchymal transition in lung squamous cell carcinoma. Med Oncol 29: 1606-1613, 2012.

27. Meng X, Wang Y, Zheng X, et al: shRNA-mediated knockdown of Bmi-1 inhibit lung adenocarcinoma cell migration and metastasis. Lung Cancer 77: 24-30, 2012.

28. Zhang X, Sun J, Wang H, et al: IGF-1R and Bmi-1 expressions in lung adenocarcinoma and their clinicopathologic and prognostic significance. Tumour Biol 35: 739-745, 2014.

29. Hiratsuka S, Nakamura K, Iwai S, et al: MMP9 induction by vascular endothelial growth factor receptor-1 is involved in lung-specific metastasis. Cancer Cell 2: 289-300, 2002.

30. Mihaylova Z, Ludovini V, Gregorg V, et al: Serum level changes of matrix metalloproteinases 2 and 9, vascular endothelial growth factor and epidermal growth factor receptor during platinum-based chemotherapy in advanced non-small cell lung cancer patients. J BUON 12: 105-111, 2007.

31. Jiang L, Wu J, Yang Y, et al: Bmi-1 promotes the aggressiveness of glioma via activating the NF-kappaB/MMP-9 signaling pathway. BMC Cancer 12: 406, 2012.

32. Li X, Yang Z, Song W, et al: Overexpression of Bmi-1 contributes to the invasion and metastasis of hepatocellular carcinoma by increasing the expression of matrix metalloproteinase (MMP)2, MMP-9 and vascular endothelial growth factor via the PTEN/PI3K/Akt pathway. Int J Oncol 43: 793-802, 2013.

33. Wagenaar SS: New WHO-classification of lung and pleural tumors. Ned Tijdschr Geneeskd 143: 984-990, 1999 (In Dutch).

34. Edge SB and Compton CC: The American Joint Committee on Cancer: the 7th edition of the AJCC cancer staging manual and the future of TNM. Ann Surg Oncol 6: 1471-1474, 2010.

35. Noguchi M: Stepwise progression of pulmonary adenocarcinoma-clinical and molecular implications. Cancer Metastasis Rev 29: 15-21, 2010.

36. Hayes DN, Monti S, Parmigiani G, et al: Gene expression profiling reveals reproducible human lung adenocarcinoma subtypes in multiple independent patient cohorts. J Clin Oncol 24: 5079-5090, 2006.

37. Silva J, García JM, Peña C, et al: Implication of polycomb members Bmi-1, Mel-18 and Hpc-2 in the regulation of p16INK4a, p14ARF, h-TERT and c-Myc expression in primary breast carcinomas. Clin Cancer Res 12: 6929-6936, 2006.

38. He S, Iwashita T, Buchstaller J, Molofsky AV, Thomas D and Morrison SJ: Bmi-1 over-expression in neural stem/progenitor cells increases proliferation and neurogenesis in culture but has little effect on these functions in vivo. Dev Biol 328: 257-272, 2009.

39. Lindström MS, Klangby U and Wiman KG: p14ARF homozygous deletion or MDM2 overexpression in Burkitt lymphoma lines carrying wild type p53. Oncogene 20: 2171-2177, 2001.

40. Song LB, Li J, Liao WT, et al: The polycomb group protein Bmi-1 represses the tumor suppressor PTEN and induces epithelial-mesenchymal transition in human nasopharyngeal epithelial cells. J Clin Invest 119: 3626-3636, 2009.

41. Stetler-Stevenson WG: Matrix metalloproteinases in angiogenesis: a moving target for therapeutic intervention. J Clin Invest 103: 1237-1241, 1999. 
42. Egeblad M and Werb Z: New functions for the matrix metalloproteinases in cancer progression. Nat Rev Cancer 2: 161-174, 2002.

43. Talvensaari-Mattila A,Pääkkö P,Höyhtyä M,Blanco-Sequeiros $G$ and Turpeenniemi-Hujanen T: Matrix metalloproteinase-2 immunoreactive protein: a marker of aggressiveness in breast carcinoma. Cancer 83: 1153-1162, 1998.
44. Wang L, Wang Q, Li HL and Han LY: Expression of MiR200a, miR93, metastasis-related gene RECK and MMP2/MMP9 in human cervical carcinoma - relationship with prognosis. Asian Pac J Cancer Prev 14: 2113-2118, 2013.

45. Bergers G, Brekken R, McMahon G, et al: Matrix metalloproteinase-9 triggers the angiogenic switch during carcinogenesis. Nat Cell Biol 2: 737-744, 2000 